\title{
Abdominal wall allotransplantation
}

\author{
Martin Molitor ${ }^{a}$, Martin Oliverius ${ }^{b}$, Andrej Sukop ${ }^{c}$
}

\begin{abstract}
Allotransplantation of vascularized composite tissue is a new field of transplantation surgery. One application of this technique is abdominal wall transplantation used as a supplementary procedure to the transplantation of visceral organs in patients with abdominal compartment deficits. As abdominal wall closure problems are experienced in around $30-40 \%$ of such patients, peer reviewed conclusions on the viability of various options, are important for an informed choice of possible procedures. This review focuses on the abdominal wall allotransplantion procedure.

Our search provided 35 appropriate references which we used to support our findings as follows: abdominal wall transplantation was performed in 33 patients at seven centres. Of these, 30 had a full thickness abdominal wall transplanted from the same donor, 3 from a second donor. Three had visceral organ transplants and in addition, the posterior sheet of the rectus muscle fascia.

In summary, our findings were that abdominal wall allotransplantation does not jeopardize the outcome of visceral organs transplantation. There is no higher risk of complications or rejection of the visceral organs. There have been no fatalities as a direct result of complications due to abdominal wall transplantation. Finally, the transplanted abdominal wall may provide an early warning of rejection before diagnostic tests on the bowel are symptomatic.
\end{abstract}

Key words: abdominal wall transplantation, vascularized composite allotransplantation

Received: March 17, 2018; Accepted: June 27, 2018; Available online: September 7, 2018

https://doi.org/10.5507/bp.2018.038

${ }^{a}$ Department of Plastic Surgery Hospital na Bulovce and $1^{\text {st }}$ Faculty of Medicine, Charles University, Prague, Czech Republic ${ }^{b}$ Department of General Surgery, $3^{\text {rd }}$ Faculty of Medicine, Charles University and Hospital Kralovske Vinohrady, Prague, Czech Republic 'Department of Plastic Surgery, $3^{\text {rd }}$ Faculty of Medicine, Charles University and Hospital Kralovske Vinohrady, Prague, Czech Republic Corresponding author:Martin Molitor, e-mail:martinmolitor1@gmail.com

\section{INTRODUCTION}

Damage to or complete loss of the abdominal wall (AW) due to injury, tumours or after repeated surgery and its complications, endangers the vitality and integrity of the visceral organs (VO). Damage also occurs when there is loss of the greater part of the VO with retraction of the AW and reduction of the intra-abdominal compartment. Additionally, visceral organ allotransplantation (VOA) may be accompanied by failure of the AW to close and sometimes VOA cannot be performed at all. Approximately $30-40 \%$ of patients with intestinal allotransplantation (IA) may experience this problem ${ }^{1,2}$.

There are various methods available for AW closure where there is a discrepancy between the volume of the transplanted organs and the intra-abdominal space: Remedial techniques include reduction of the transplanted organs, splenectomy and/or selection of a donor smaller than the recipient: Expansion techniques include sequential transplantation, peritoneal expansion and use of tissue expanders.

For reconstruction and substitution, component separation, skin only suturing, sequential closure and an open abdomen with skin transplantation can be used. This also includes the use of flaps, synthetic meshes or skin replacements ${ }^{1.4}$. If these options are exhausted, the remaining alternative is abdominal wall allotransplantation (AWA) $\left(\right.$ ref. $\left.^{5-8}\right)$. To date, the reason for all AWAs was insufficient recipient abdominal wall tissue after a VOA. This review focuses on the results of AWA.

\section{RESULTS}

There were a total of 1874 hits with the key words chosen. Of these 1810 were eliminated on the basis of relevance. Of the remaining 64, 29 more were excluded due to duplication or peripheral topic and one was dropped as the paper had been retracted from publication. This left us with 35 valid articles on which to base this review.

\section{Classification of the $\mathrm{AW}$ as a transplant}

The AW from the plastic surgery perspective is a vascularized musculo-fascio-adipo-cutaneous flap. It contains peritoneum, muscles with fascia, fatty tissue and skin. It is transplanted as a discrete organ with its vascular supply. From the transplantation surgery perspective, it is classified as a "Vascularized Composite Allotransplant" (VCA) similar to a hand or face transplant.

In the United Network for Organ Sharing (UNOS) registry (USA), VCA was added to the list in July 2014 and there are nine criteria which must be fulfilled;

1. tissue is vascularized and requires connection of vessels for its vitality and functionality

2. it contains several types of tissues

3. it is obtained from a living donor as an anatomicalstructural unit 
4. it is transplanted to a human recipient as an anatomical-structural unit

5. there is minimal tissue manipulation

6. it is used for homologous replacement

7. it is not combined with an artificial device

8. it can only be stored for a limited time

9. it requires immunosuppressive therapy ${ }^{9}$

\section{AWA in animal experiments}

AWA is technically possible on a unilateral vascular system and with sufficient immunosuppressive therapy (IT) long term survival without rejection is possible ${ }^{10,11}$. It has been found that longer term survival of both grafts can be achieved using a combination of AWA with vascularized bone marrow transplantation ${ }^{12}$. It is noted that anastomosis of the lower epigastric vessels bilaterally ensures perfusion of the whole transplant while partial ischemia may occur in unilateral anastomosis. AWAs involve a greater area of skin than facial transplantation, however chimerism is higher in face transplantation, probably due to a greater content of lymphatic tissue ${ }^{13,14}$. After an AWA without any reconstruction of the nerves, there is significantly reduced muscle mass, myofibril cross-sectional area and reinervation ${ }^{15}$.

\section{AWA in human cadaver dissection studies}

Studies have examined the extent of perfusion of the AW resulting from alternatively the deep inferior epigastric artery or the common stem of the external iliac artery with the deep inferior epigastric artery, the deep circumflex iliac artery, the superficial epigastric artery and the superficial circumflex iliac artery. It was found that the deep circumflex iliac artery significantly improves perfusion of the lateral part of the AW (ref. ${ }^{16}$ ). Innervation of the AW is provided by thoracolumbar nerves Th7-L4. It is possible to dissect 3-6 nerves that are 6-7 cm long with a diameter of approximately $2 \mathrm{~mm}$ (ref. ${ }^{17,18}$ ). After denervation of the AW there is a significantly reduced muscle tension strength, reduced muscle thickness and diameter of muscle fibres ${ }^{19}$. It was noted that innervation of the AW for sensory purposes was not essential as encapsulating the VOA was its primary purpose. However, one case report described a burn injury of the AWA after clinical transplantation as a result of skin hypesthesia ${ }^{20}$.

\section{AWA in clinical practice}

AWA was performed for the first time in 2001 in the USA, in nine patients in association with VOA. Vascular anastomoses were carried out macroscopically to the common iliac vessels, in three cases to the aorta and the inferior vena cava. Twice the AWA was performed as a delayed procedure from another donor. Two and a half years after transplantation, four patients survived. Three died due to sepsis, one due to bowel rejection and one due to primary bowel dysfunction. The AW had to be removed twice due to ischemia. In one case secondary healing occurred. In the second case the AW re-transplantation was performed successfully but the patient died due to sepsis. There were two cases of isolated rejection of the bowel and two cases of isolated rejection of the AW, always in patients who had the AWA from a separate donor ${ }^{21-23}$.

The microsurgical technique of AWA was first carried out in Italy in 2007 in three patients. Anastomoses were performed between the deep inferior epigastric vessels bilaterally in two cases. In one case, only the unilateral vascular pedicle was used but it was successful, with no signs of ischemia. The AW healed in all three patients without rejection. Bowel rejection occurred in two patients. One patient died one year after transplantation due to post-transplant lymphoprolipherative disease (PTLD) the other two patients survived ${ }^{24}$. One patient had a recurrent episode of acute graft versus host disease (GVHD) however this was successfully treated with extracorporeal photopheresis and steroids ${ }^{25}$.

A review article from 2009 evaluated the results of both the previous teams with post-surgery observation extending for 2-7 years ${ }^{8}$. Five of fourteen patients survived. None of the patients had died due to direct complications associated with AWA.

Another AWA with VOA was performed in Indianapolis in a young woman who had juvenile dermatomyositis. The VOA was temporarily covered with silastic mesh and the following day, an AWA was carried out with tissue from another donor. Anastomoses were performed utilising femoral vessels ${ }^{26}$.

It was surmised in two reports that simultaneously performing VOA and an AWA where anastomosis of the AWA are done after the VOA is completed, increases the time of AWA ischemia with an increased risk of a subsequent acute rejection of both grafts or shorter graft survival $^{27,28}$. The transplantation strategy was subsequently modified in Oxford and the AW was temporarily vascularized with an anastomosis to the forearm vessels in six patients. After completion of the VOA, the overall condition of the patient and vessels in the pelvic area were evaluated. In favourable cases, the AW was disconnected from forearm vessels and attached with anastomosis of the epigastric vessels to the pelvic vessels of the recipient at the end of surgery. One patient revealed signs of hemodynamic instability after IA and the AW was not disconnected from the forearm. In one patient, ischemia of the AW occurred after anastomoses to the pelvic vessels, and connection to the forearm vessels was restored. Four weeks later the AW was disconnected from the forearm vessels in both latter patients. Supportive perfusion was carried out by anastomoses between upper epigastric vessels. Isolated rejection of the AW was diagnosed in three patients. In two patients a second episode occurred, in one case with bowel rejection. One patient developed GVHD. Six months after transplantation five patients survived, one patient died due to sepsis ${ }^{29-33}$.

Another study compared a group of 15 patients with VOA and a group of 14 patients with simultaneous VOA and AWA from the same donor. Survival was similar in both groups and the differences were not significant. However, comparing the frequency and duration of repeated hospitalisation, better results were obtained in patients with simultaneous transplantations. Rejection of 
the AW occurred in 5 patients. Four of these re-attended two days after the first signs of rejection and histological examination revealed rejection of the AW only. The fifth patient presented after a week of persistent diarrhoea. Histology revealed both rejection of the AW and also the transplanted intestine. Four patients had GVHD. Absence of generalized skin exanthema on the AW skin helped with the diagnosis in both patients with AWA. The authors concluded that simultaneous AWA and VOA offers four advantages. (a) It is possible to perform a comfortable closure of the AW; (b) the skin of the AW may be used as an early marker of intestinal rejection; (c) it can help to clarify GVHD and (d) it can be useful for differential diagnosis between intestinal inflammation and rejection $^{34,35}$.

Haveman et al. have reported one case of AWA carried out in conjunction with IA in a patient with ultra-short bowel syndrome as a result of Crohn's disease. At the time of reference the patient had survived for six months ${ }^{36}$.

The AW may also be transplanted in a form of a split graft where only some layers are utilised. Three paediatric patients underwent liver transplantation together with the posterior fascia of the rectus abdominis muscles. The posterior fascia was connected with the liver by the falciform ligament, which contains nutritive vessels. The fascia remained vital with no signs of rejection. One patient died 51 days after the procedure due to sepsis, two having survived for 4 and 16 months at the time of reporting ${ }^{37,38}$.

Use of a non-vascularized fascia - Abdominal Wall nonVascularized non-Composite Allograft - was described in two studies. Healing in patients was reported as favourable, however exchange for a synthetic mesh or a new fascia was necessary in some cases. Despite the higher incidence of wound infection, there was no correlation with the failure rate of the procedure ${ }^{39,40}$.

\section{The selection of donor for AWA}

The criteria for AW donors are similar to those for VO donors and have to comply with the legal regulations of the particular country where the procedure is performed. Age limits are not given; more important is the biological vitality of the tissue. Obese donors (Body Mass Index BMI more than 30) should be excluded as well as donors with a serious injury to the abdominal wall or excessive scaring from previous abdominal procedures. From an aesthetic viewpoint, it is advisable to choose donors of similar skin and hair colour, weight and musculature but due to the seriousness of the condition and the limited pool of donors this is not always possible. Some recipients may also have psychological issues over receiving an abdominal wall that is extensively tattooed and/or decorated with multiple piercings.

\section{Immunosuppressive therapy in clinical AWA}

The immunosuppressive regimen in AWA is similar to that used in other VCA or organ transplantation procedures. Induction immunosuppression usually starts with alemtuzumab or daclizumab ${ }^{8,21,24,30,34}$. Maintenance immunosuppression is usually a combination of tacrolimus, mycophenolate mofetyl and prednisone. Sometimes only tacrolimus with corticosteroids is used ${ }^{8,21,30}$ or even monotherapy with tacrolimus $\mathrm{s}^{21,24,34}$. For rejection periods, boluses of corticosteroids are effective with or without increasing the dose of other immunosupressants. In the case of GVHD, boluses of corticosteroids are efficacious as well. For persistent episodes, extracorporeal photophoresis can be used with good result ${ }^{25}$.

\section{Rejection of the AW}

All foreign human tissues cause a reaction of the recipient immune system to a different degree of antigenicity and are subject to rejection by various mechanisms. There is a rejection ladder that has been proposed for individual tissues. Skin is highest followed by bone marrow, subcutaneous tissue, bone and then muscle. Low immunogenicity is a feature of vessels, tendons, cartilage and nerves. VCA, as a complex organ, triggers milder rejection than its individual tissue groups transplanted separately ${ }^{41,42}$.

The difference in tissue immunogenicity may also manifest as a split tolerance phenomenon. Here, one tissue class of VCA may be tolerated while another is reject$\mathrm{ed}^{43}$. This phenomenon was demonstrated experimentally where it was shown that the skin of a limb was rejected while other tissues remained viable ${ }^{44}$. Split tolerance has also been confirmed in clinical practise in patients with a transplanted hand (from France, Austria and China) (ref. $\left.{ }^{45}\right)$.

\section{The AW skin rejection and its classification}

Currently it is recommended that we use a scoring system, which was developed in consensus at a VCA symposium in 2007. (Banff's Scoring System - BSS). The BSS

Table 1. Banff's histological scoring system for skin rejection (2007).

\begin{tabular}{rll}
\hline Stage & Description & Histological findings \\
\hline 0 & No rejection & No infiltrate or sporadic inflammatory infiltrate \\
I & Mild rejection & Mild perivascular infiltrate without impairment of epidermis \\
II & Moderate rejection & Moderate perivascular inflammation with/without epidermal reaction \\
III & Severe rejection & Dense inflammation including epidermis with epithelial apoptosis with dyskeratosis and/or \\
& & keratinolysis \\
IV & Necrotizing rejection & Necrosis of epidermis and other skin structures \\
\hline
\end{tabular}

Skin rejection scale as a consensus from Banff's VCA symposium in 2007. 
Table 2. Kanitakis's visual skin rejection scale.

\begin{tabular}{lll}
\hline Stage & Description & Visual skin changes \\
\hline 0 & No rejection & Skin has normal appearance \\
I & Mild rejection & Skin without changes or with pinkish maculae \\
II & Moderate rejection & Erythematous spread of macular lesions \\
III & Severe rejection & Papular erythema, papulae may be confluent into map-shaped plaques \\
IV & Necrotizing rejection & Skin swelling with reddish enlarged lesions, erosions and necrotic lesions \\
\hline
\end{tabular}

Correlation between visual skin changes and the stage of rejection according to Kanitakis (2007).

expresses severity of rejection and enables observation of its development (Table 1.) $\left(\right.$ ref. $\left.^{46}\right)$.

Visual changes of the skin were not classified at this symposium due to their variability and diversity. However considering the potential clinical significance we note here the grading of histological stages with visual changes as reported by Kanitakis in 2007 (Table 2.) (ref. ${ }^{47}$ ).

\section{Skin of AWA as a marker of VOA rejection}

Skin is a primary target for rejection. It is also readily available for visual examination, so signs of acute rejection may be detected early without the need of biopsy or laboratory tests. It follows logically, that skin could be used as an early marker of a possible rejection event to the whole VCA and/or VOA. Experimental transplantation of limbs in combination with skin grafts have confirmed this hypothesis. Visual and histological signs of rejection manifested significantly earlier on a simplex skin graft than on a limb as a complex allograft ${ }^{48}$. Further, two clinical studies described simultaneous transplantation of a skin graft and a kidney. The skin graft was used as a marker of rejection but it was found that the survival of both grafts was the same ${ }^{49,50}$. An Italian team used the skin graft as a marker of rejection in a clinical transplantation of a hand. Rejection in all patients manifested first on the skin graft prior to that of the transplanted hand ${ }^{51}$. There was however no difference in the onset of rejection between transplanted grafts when facial transplantation was performed in combination with vascularized forearm skin flap transplantation ${ }^{52}$.The reason may be that a vascularized skin flap is composed of similar tissues to that of a facial allograft.

In simultaneous AWA and IA, it is difficult to decide which graft represents a greater immunological burden. Bowel mucosa has similar immunogenicity to skin and the differences in onset of rejection in skin and bowel may be insignificant ${ }^{53,54}$. In patients from Miami isolated rejection of the bowel was found twice and isolated rejection of the $\mathrm{AW}$, twice as well ${ }^{21,55}$. In patients from Bologna rejection of the bowel occurred twice but no rejection of the AW occurred ${ }^{24}$. Authors from Oxford reported isolated rejection of the AW four times and rejection of the AW simultaneously with the bowel only once ${ }^{7,29,34,56}$. Current experiences show that AWA and IA may behave independently with regards to rejection. Their rejection occurs at approximately the same frequency and often as isolated events. It is reasonable to conclude that: (a) rejection of the skin in an AWA procedure does not always precede rejection of the VOA: (b) in cases where there is rejection of the skin, organ rejection may not necessarily follow.

\section{CONCLUSION}

According to the currently available literature, AWA has been performed in seven centres on 33 patients. Full thickness abdominal wall was transferred in 30 patients with restoration of circulation by vascular anastomoses between the vessels of the graft and the recipient. In 3 patients only the posterior sheet of the rectus muscles fascia was transferred with circulation provided by the vessels of the falciform ligament associated with liver transplantation. In 30 patients, AWA and VOA were from the same donor, in 3 patients from another.

The goal of AWA performed to date was to secure safe closure of the AW after the VOA. This was a "necessary for survival" secondary procedure and for this reason, there was no ethical consideration, such as may occur with transplantations of other VCAs (e.g. hand or face), where it introduces a significant lifelong risk of immunosuppressive therapy from a procedure that just serves to improve the quality of life. Harvesting of the AW does not endanger harvesting of other organs, because they have different vascular supplies. Simultaneous AWA and VOA extend the procedure by approximately two hours. The AW may be transferred using macroscopic or microscopic techniques on the iliac, femoral or deep inferior epigastric vessels. Transplantation of the AW may be delayed if needed and performed using tissue from a second donor. There is no need for rehabilitation, because to date, the function of the graft is only to seal the abdomen.

AWA is to date only indicated in patients with a seriously insufficient abdominal compartment, necessitating VOA. Indications may be extended in future to patients with, for example, extensive abdominal hernias, abdominal injuries or maybe congenital malformancies. In the event of such cases it will be necessary to modify the surgical technique to achieve sensory and motor reinnervation of the AW.

\section{Search strategy and selection criteria}

We carried out a literature search for the period from 1990-2017 using the bibliography of the databases: Pubmed, SCOPUS, Web of Science and Google Scholar. Search terms included: abdominal wall transplantation 
and abdominal wall allotransplantation. Since these procedures are specialised and publications on this issue are rare, the initial exclusion criteria were narrow. To encompass more data, we also used abstracts and poster references. The exclusion criteria were (a) duplicate references, (b) references where AWA was peripheral to the topic and (c) invalid or irrelevant references.

\section{ABBREVIATIONS}

AW, Abdominal Wall; AWA, Abdominal Wall Allotransplantation; BMI, Body Mass Index; BSS, Banff's Scoring System; GVHD, Graft Versus Host Disease; IA, Intestinal Allotransplantation; IT, Immunosuppressive Therapy; PLTD, Post-Transplant Lymphoprolipherative disease; UNOS, United Network for Organ Sharing; USA, United States of America; VCA, Vascularized Composite Allotransplantat; VO, Visceral Organs; VOA, Visceral Organs Allotransplantation.

Author contribution: All authors contributed equally to preparing the manuscript.

Conflict of interest statement: Authors declare that there are no conflicts of interest regarding the publication of this article.

\section{REFERENCES}

1. Zanfi C, Cescon M, Lauro A, Dazzi A, Ercolani G, Grazi GL, Del Gaudio M, Raviaoli M, Cucchettii A, La Barbara G, Zanello M, Cipriani R, Pinna AD. Incidence and management of abdominal closure related complications in adult intestinal transplantation. Transplantation 2008;85:1607-9.

2. Gerlach UA, Pascher A. Technical advances for abdominal wall closure after intestinal and multivisceral transplantation. Curr Opin Organ Transplant 2012;17:258-67.

3. Alexandrides IJ, Liu P, Marshall DM, Nery JR, Tzakis AG, Thaller SR. Abdominal wall closure after intestinal transplantation. Plast Reconstr Surg. 2000;106(4):805-12.

4. Carlsen BT, Rudkin GH, Farmer DG. Complicated abdominal wall closure in intestinal transplant recipient. Curr Opin Organ Transplant 2005; 10:128-31.

5. Avashia YJ, Mackert GA, May B, Erdmann D, Ravindra KV. Abdominal Wall Transplantation. Curr Transplant Rep 2015;2:269-75.

6. Berli JU, Broyles JM, Lough D, Shridharani SM, Rochlin D, Cooney DS, Lee WP, Brandacher G, Sacks JM. Current concepts and systematic review of vascularized composite allotransplantation of the abdominal wall. Clin Transplant. 2013;27(6):781-89.

7. Giele H, Vaidya A, Reddy S, Vrakas G, Friend P. Current state of abdominal wall transplantation. Curr Opin Organ Transplant 2016;21(2):159-64.

8. Selvaggi G, Levi DM, Kato T, Madariaga J, Moon J, Nishida S, Tzakis AG. Expanded Use of Transplantation Techniques: Abdominal Wall Transplantation and Intestinal Autotransplantation. Transpl Proc 2004;36:1561-3.

9. Alcorn JB. Memorandum: Use of VCA Grafts to Reconstruct the Abdominal Wall. Available from: http://optn.transplant.hrsa.gov/ media/1159/vca_abdominal_wall_memo.pdf

10. Lao WW, Wang YL, Ramirez AE, Cheng HY, Wei FC. A New Rat Model for Orthopic Abdominal Wall Allotransplantation. Plast Reconstr Surg Global Open 2014;2(4):e136.

11. Quigley MA, Fletcher DR, Zhang W, Nguyen VT. Development of a Reliable Model of Total Abdominal Wall Transplantation. Plast Reconstr Surg 2013;132(4):988-94.

12. Ramirez AE, Cheng HY, Lao WW, Wang YL, Wen CJ, Wallace CG, Lin CF,
Shih LY, Chuang SH, Wei FC. A novel rat full-thickness hemi-abdominal wall/hindlimb osteomyocutaneous combined flap: influence of allograft mass and vascularized bone marrow content on vascularized composite allograft survival. Transpl Int 2014;27(9):977-86.

13. Nasir S, Bozkurt M, Klimczak A, Semionow M. Large Antigenic Skin Load in Total Abdominal Wall Transplants Permits Chimerism Induction. Annals Plast Surg 2008;61(5):572-9.

14. Nasir S. Abdominal Wall Transplant Models. In. MZ Siemionow Eds. Plastic and Reconstructive Surgery: Experimental Models and Research Designs. e-book, Springer-Verlag London 2015; p349-60.

15. Broyles JM, Sarhame KA, Tuffaha SH, Cooney DS, Lee WPA, Brandacher G, Sacks JM. Plast Reconstr Surg 2015;136(4):728-37.

16. Light D, Kundu N, Djohan R, Quintini C, Gandhi N, Gastman BR, Drake R, Semionow M, Zins JE. Total Abdominal Wall Transplantation: An Anatomical Study and Classification System. Plast Reconstr Surg 2017;139(6):1466-73.

17. Broyles JM, Berli J, Tuffaha SH, Sarhane KA, Cooney DS, Eckhauser FE, Lee WP, Brandacher G, Singh DP, Sacks JM. Functional abdominal wall reconstruction using an innervated abdominal wall vascularized composite tissue allograft: a cadaveric study and review of the literature. J Reconstr Microsurg. 2015;31(1):39-44.

18. Sigh DP, Mavrophilipos VD, Zapora JA, Berli J, Broyles J, Chopra K, Sabino J, Matthews J, Buckingham B, Maddox JS, Bluebond-Langner R, Silverman RP. Novel Technique for Innervated Abdominal Wall Vascularized Composite Allotransplantation. Eplasty 2014;14:e34.

19. Jin J, Williams CP, Soltanian H, Smith MK, Pearl J, Sanabria J, Rosen MJ. Use of Abdominal Wall Allotransplantation as an Alternative for the Management of End Stage Abdominal Wall Failure in a Porcine Model. J Sur Res 2010;162:314-20.

20. Mannu GS, Vaidya A. Thermal trauma to abdominal wall vascularized composite allotransplant. BMJ Case Rep 2014; pii: bcr2013202692. doi: 10.1136/bcr-2013-202692

21. Levi DM, Tzakis AG, Kato T, Madariaga J, Mital NK, Nery J, Nishida S, Ruiz P. Transplantation of the abdominal wall. The Lancet 2003;361:2173-6.

22. Sue GR, Narayan D. Niche Reconstructive Techniques for Complex Abdominal Wall Reconstruction: A Review. Am Surg 2014;80(4):32734.

23. Bejarano PA, Levi D, Nassiri M, Vincek V, Garcia M, Weppler D, Selvaggi G, Kato T, Tzakis A. The Pathology of Full-thickness Cadaver Skin Transplant for Large Abdominal Defects. Am J Surg Pathol 2004;28(5):670-5.

24. Cipriani R, Contedini F, Santoli M, Gelati C, Sgarzani R, Cucchetti A, Lauro A, Pinna AD. Abdominal Wall Transplantation with Microsurgical Technique. Am J Transpl 2007;7:1304-7.

25. Lauro A, Arpinati M, Zanfi C, Morelli MC, DErrico-Grigioni A, Bagni A, Dazzi A, Pironi L, Pinna AD. Extracorporeal Photopheresis for Chronic GVHD: Case Report After Adult Bowel-Abdominal Wall Transplantation. Transplantation 2013;97(2):e9-e10.

26. Schimmelpfennig R, Kritzmire S. [NM-290] Multivisceral and abdominal wall transplantation after gastrointestinal perforation in juvenile dermatomyositis: a case report. - Available from: http://www2.pedsanesthesia.org/meetings/2013winter/syllabus/submissions/stracts/ nonmod/NM-290.pdf.

27. Khalifian S, Cooney D, Lee WPA, Brandacher G. The role of ischaemia reperfusion injury in reconstructive transplantation. J Transplant Technol Res 2013;S3:004.

28. Mikhalski D, Wissing KM, Ghisdal L, Broeders N, Touly M, Hoang AD, Loi P, Mboti F, Donckier V, Vereerstraeten P, Abramowicz D. Cold ischemia is a major determinant for acute rejection and renal graft survival in the modern era of immunosuppression. Transplantation 2008;85:S3-S9.

29. Giele H, Bendon C, Reddy S, Ramcharan R, Sinha S, Friend P, Vaidya A. Remote Revascularization of Abdominal Wall Transplants Using the Forearm. Am J Transpl 2014;14:1410-6.

30. Allin BSL, Ceresa CDL, Issa F, Casey G, Espinoza O, Reddy S, Sihna S, Giele H, Friend P, Vaidya A. A Single Center Experience of Abdominal Wall Graft Rejection After Combined Intestinal and Abdominal Wall Transplantation. Am J Transpl 2013;13:2211-5.

31. Mannu GS, Vaidya A. An interesting rash following bowel and abdominal wall transplantation. BMJ Case Rep 2013;2013. pii: bcr2013200951. doi: 10.1136/bcr-2013-200951

32. Mannu GS, Vaidya A. Graft versus host disease following small bowel 
and abdominal wall transplantation. BMJ Case Rep 2014;2014 pii: bcr2014205983. doi: 10.1136/bcr-2014-205983

33. Vrakas G, Arantes R, Boffa C, Reddy S, Friend P, Giele H, Vaidya A. Abdominal Wall Transplantation to Complement Intestinal Transplantation. Transplant 2014;98(Suppl):44. (Transplantation Meeting Abstract 2293).

34. Gerlach UA, Vrakas G, Sawitzki B, Macedo R, Reddy S, Friend PJ, Giele $\mathrm{H}$, Vaidya A. Abdominal Wall Transplantation: Skin as a Sentinel Marker for Rejection. Am J Transpl 2016;16(6):1892-900.

35. Barnes J, Issa F, Vrakas G, Friend P, Giele H. The abdominal wall transplant as a sentinel skin graft. Curr Opin Organ Transplant 2016;21(5):536-40.

36. Haveman JW, Tempelman TM, Hofker HS, Khoe PC, Dijkstra G, Werker PM. First combined intestinal and abdominal wall transplantation in the Netherlands. Ned Tijdschr Geneeskd 2016;160:A9788.

37. Agarwal S, Dorafshar AH, Harland RC, Millis JM, Gottlieb LJ. Liver and Vascularized Posterior Rectus Sheath Fascia Composite Tissue Allotransplantation. Am J Transpl 2010;10:2712-6.

38. Ravindra KV, Martin AE, Vikraman DS, Brennan TV, Collins BH, Rege AS, Hollenbeck ST, Chinappa-Nagappa L, Eager K, Cousino D, Sudan DL. Use of vascularised posterior rectus sheath allograft in paediatric multi-viseceral transplantation: report of two cases. Am J Transp 2012;12:2242-6.

39. Gondolesi G, Selvaggi G, Tzakis A, Rodrígues-Laiz G, GonzálesCampaňa A, Fauda M, Angelis M, Levi D, Nishida S, lyer K, Sauter B, Podesta L, Kato T. Use of the Abdominal Rectus Fascia as a Nonvascularized Allograft for Abdominal Wall Closure After Liver Intestinal and Multivisceral Transplantation. Transplantation 2009;87(12):1884-8.

40. Farinelli PA, Fubio JS, Aguirre N, Rumbo C, Solar H, Ramisch DA Gondolesi GE. Use of Abdominal Wall, Non-Vascularized, NonComposite Allograft After Abdominal Organ Transplantation. Update on Long Term Follow up of a Single Center Series. Transplantation 2017:101(S6-2):S23-S24.

41. Duguesnoy RJ. Is histocompatibility testing needed for composite tissue transplantation? Transplant Proc 1998;30:2724-8.

42. Lee WP, Yaremchuk MJ, Pan YC, Tandolph MA, Ta CM, Weiland AJ. Relative antigenicity of components of a vascularized limb allograft. Plast Reconstr Surg 1991;87(3):401-11.

43. Billingham R, Brendt L. Quantitative studies on tissue transplantation immunity: IV. Induction of tolerance in newborn mice and studies on the phenomenon of runt disease. Philos Trans R Soc Lond Biol Sci 1959;242:39.

44. Mathes D, Randolph M, Solari M, Nazzal J, Nielsen GP, Scott AJ, Sachs
D, Lee WPA. Split tolerance to a composite tissue allograft in swine model. Transplantation 2003;75(1):25-31.

45. Schneeberger S, Gorantla VS, Hautz T, Pulikkottil B, Margreiter R, Lee WPA. Immunosuppression and Rejection in Human Hand Transplantation. Transpl Proc 2009;41:472-5.

46. Cendales, LC, Kanitakis J, Schneeberger S, Burns C, Ruiz P, Landin $L$, Remmelink M, Hewitt CW, Landgren T, Lyons B, Drachenberg CB, Solez K, Kirk AD, Kleiner DE, Racusen L. The Banff 2007 Working Classification of Skin-Containing Composite Tissue Allograft Pathology. Am J Transpl 2008;8:1396-400.

47. Kanitakis J. Skin Rejection in Human Hand Allografts: Histological Findings and Grading System. In M. Lanzetta, JM. Dubernard Eds. Hand Transplantation, Springer-Verlag Italia 2007, p249-58.

48. Zamfirescu DG, Owen E, Lascar I, Molitor M, Zegrea I, Popescu M Bishop GA, Lauer CA, Simionescu M, Climov M, Lanzetta M. Sentinel skin allograft-a reliable marker for monitoring of composite tissue transplant rejection. Transpl Proc 2009;41(2):503-8.

49. Wendt JR, Ulich TR, Ruzics EP, Hostetler JR. Indefinite survival of human skin allografts in patients with long-term immunosuppression. Ann Plast Surg 1994;32:411-17.

50. Haberal M, Gulay H, Arslan G, Sert S, Altunkan S, Bilgin N. ABOincompatible kidney transplantation with donor-specific skin graft. Ren Fail 1991;13(2-3):103-10.

51. Lanzetta M, Rovati L. Monitoring Rejection with a Distant Sentinel Skin Graft. In M. Lanzetta, JM. Dubernard Eds. Hand Transplantation, Springer-Verlag Italia 2007, p263-8.

52. Kueckelhaus M, Fischer S, Lian CG, Bueno EM, Marty FM, Tullius SG, Pribaz JJ, Murphy GJ, Pomahac B. Utility of sentinel flaps in assessing facial allograft rejection. Plast Reconstr Surg 2015;135(1):250-8.

53. Prop J, Nieuwenhuis P, Wildevuur CRH. Lung allograft rejection in the rat. I: accelerated rejection caused by graft lymphocytes. Transplantation 1985;40:25-30.

54. Zhang Z, Zhu L, Quan D, Garcia B, Ozcay N, Duff J, Stiller C, Lazarovits A, Grant D, Zhong R. Pattern of liver, kidney, heart and intestine allograft rejection in different mouse strain combinations. Transplantation 1996;62:1267-72.

55. Selvaggi G, Levi DM, Cipriani R, Sgarzani R, Pinna AD, Tzakis AG. Abdominal Wall Transplantation: Surgical and Immunologic Aspects. Transpl Proc 2009;41:521-2.

56. Bendon Ch, Reddy S, Friend P, Vaidya A, Giele H. The Use of Sentinel Flaps to Monitor Organ Rejection in Visceral Transplants. Abstract from 12th. Congress of IHCTAS, Philadelphia April 15-18, 2015, MO-03. Available from: http://journals.lww.com/transplantjournal/Fulltext/2015/06002/Abstracts_from_the_12th_Congress_of_ the.1.aspx. 